Peer-Reviewed Article

ISSN: 2162-3104 Print/ ISSN: 2166-3750 Online

Volume 6, Issue 2 (2016), pp. 431-450

(C) Journal of International Students

http://jistudents.org/

\title{
Ways to Promote the Classroom Participation of International Students by Understanding the Silence of Japanese University Students
}

\author{
Soonhyang Kim \\ University of North Florida, USA \\ Burcu Ates \\ Sam Houston State University, USA \\ Yurimi Grigsby \\ Concordia University Chicago, USA \\ Stefani Kraker \\ Queens College, City University of New York, USA \\ Timothy A. Micek \\ Ohio Dominican University, USA
}

\begin{abstract}
The authors explored the role of silence and deciphered its meaning and usefulness as a teaching and learning strategy for Japanese students through a survey of Japanese university students in their home country. This study has revealed that participant responses were evenly divided among comfortable with silence, uncomfortable with silence, and dependent on familiarity with the person. The use of silence by Japanese students varies on a highly individualized basis, not only by culture. The interlocutor is the significant factor, not the topic of conversation, for their comfort with silence. This study also


suggests that silence can be used in addition to verbal participation as a form of engaged learning and active participation.

Keywords: Silence; Class Participation, Japanese Students; International Students; Engaged Learning; Teaching Strategy

I've begun to realize that you can listen to silence and learn from it. It has a quality and a dimension all its own.

- Chaim Potok, The Chosen

Silence has long been used as a means of communication across cultures. We can find evidence of this through idioms around the world. For example, "Silence is golden," although not verified, is believed to have originated in ancient Egypt, and is a popular American idiom to indicate circumstances where saying nothing is preferable to speaking. The exact expression exists in other languages, for example, chinmoku wa kane nari (Japanese). The sentiment of allowing quiet and stillness the freedom to intervene in dialogue and conversation permeates cultural divides.

While the value of silence may be recognized in certain contexts, it may not always be welcomed in United States (U.S.) classrooms. The difficulty for teachers may be that silence is rather difficult to interpret in the classroom (Harumi, 2011). Teachers might erroneously conclude that silence equals disengagement, though quite the opposite may be true. Silence may be more easily associated with loss of interest than its counterpart of active voice, but it is equally true that disengagement can also be manifested through talking that seems like rambling (Kim, 2008). Put differently, "neither talk nor silence is a proxy for participation or disengagement" (Schultz, 2012, p. 80). This is especially true when students from other countries and cultures enter into U.S. classrooms.

This study examines silence as viewed by Japanese students by surveying university students in their home countries to understand the silence of Japanese university students in U.S. classrooms. Through survey data of Japanese students, we explore the role of silence, decipher its meaning and usefulness as a teaching and 
learning strategy, and provide evidence that silence can be used as another form of engaged learning and active participation in addition to verbal participation.

\section{SILENCE: JAPANESE PERSPECTIVES}

Japan is the seventh largest country of origin for international students in the U.S., with almost 20,000 Japanese students studying at postsecondary institutions in 2011/2012, making up 3\% of the total number of international university students (Institute of International Education, 2012). Japanese students, in particular, are often described as attaching "especially strong values to silence" (Nakane, 2005, p. 77), and as standing out in their silence "not only in comparison with Southern Europeans or New Yorkers but with East Asian neighbors like Koreans and Chinese as well" (Lebra, 1987, p. 344). In exploring the topic of silence in Japan and the misinterpretation of silence by outsiders, Jones (2011) found it to be a complex phenomenon "which lies primarily in the linguistic and cultural differences between cultures" (p. 17).

Lebra (1987, 2007) addressed the cultural importance of Japanese silence and identified it within four dimensions: truthfulness, social discretion, embarrassment, and defiance. According to Lebra, silence has been associated with truthfulness in Japan, a belief originating from Zen Buddhism that encouraged silence as a pathway to enlightenment and stressed the inability to reach enlightenment by talking about it. Silence referring to social discretion is used as a technique to demonstrate politeness, in that silence can help preserve one's public self-image, or face, while still engaging in dialogue. Silence relating to embarrassment and defiance is marked by high levels of ambiguity, but Lebra explains the former as a way to avoid embarrassment surrounding the spoken affections between husband and wife (they are supposed to know each other so well that they are of one body and thus can communicate without words), and the latter as a possible non-verbal expression of aggression, among other possible gestures, leading to confusion for both non-natives and natives. Because the reasons behind silence can be many, those who are unfamiliar with the highly contextualized situations in which it occurs will often misunderstand its complex nature. For the Japanese, 
"sasshi (a listener's ability to guess what a person is inferring) is considered an important paralinguistic skill" (Lebra, 2007, p. 21) that may include correctly translating nonverbal behaviors like body language, eye rolls, sighs, or groans.

Although it may not provide deep insights into the reasons behind silence, existing research has shed light on its many possible interpretations through closer observation of the topic. Japanese students in Nakane's (2005) case studies found silence to be a result not only of cultural conditioning but also of immediate contextual factors related to the classroom environment. The author found that while trying to be helpful by filling the silence caused by the student needing time to organize his or her thoughts, other peers or the lecturer spoke in place of the designated Japanese student speaker. This action resulted in a sequence change and shift in the focus of instruction, which led to further silence and a delay in response by Japanese students. For Japanese students unfamiliar with voluntary class participation, they may not interact "without an explicit cue for participation" (p. 94). Nakane explained that Japanese silence serves as linguistic "politeness strategies, cognitive processing time, or constituents of interactive style" (p. 95). Therefore, their silences should not be ignored as they could also produce a "negative effect on Japanese students' self-confidence in classroom interaction" (p. 95) as well as affect the rapport between Japanese students, domestic peers, and instructors, "reinforcing and creating stereotypes" (p. 95).

In Mayuzumi, Motobayashi, Nagayama, and Takeuchi's (2007) study, four participants described their experience of being female Japanese students at a Canadian university. Using an autobiographical methodology within a dialogue format, the members described in detail what it is like to be silent and to be silenced. As one person said, Western orientations encourage talking more than listening. The participants observed that one receives higher participation marks the more one talks in class. Because they did not feel able to jump into class discussions freely, they blamed themselves. Two of the participants even described shedding tears as a result of the experience. This experience caused their self-esteem to drop, which further debilitated their ability to speak up in class.

Other instances Mayuzumi et al. described involved being actively silenced. For instance, when one of the participants tried to 
ask her professor for help regarding his lecture in a political science class, he interrupted her and said 'Go back to ESL class' (p. 585). The professor did not attempt to help the student or question his customary style of lecturing. Neither did the professor reflect on his tendency to mumble, or consider the Japanese student's unfamiliarity with U.S. politics. Instead, he placed all blame on the student and what he immediately perceived was the only problem: her lack of English skills. Ironically, another participant mentioned that she was silenced during a discussion about silence, when a professor appropriated a rather simplistic analysis of the reason behind her quietness, chalking it up to her being an Asian female, imposing on her a stereotype he had of the student. While she felt the teacher's interpretation was not totally accurate, she did not argue or deny it because she did not want to interrupt the class or slow down the flow of conversation. In this way, stereotypes and a simplistic explanation of the issue remain a persistent problem for students struggling with the issue of silence.

Along the same line, Morita's (2004) findings about the reasons behind the students' silence demonstrated the danger of making assumptions. When assumptions are made (in this case it could be that all the students were Asian women, and their silence was from gender or cultural roles), the real reasons that motivate or explain their behavior, are dismissed. In Morita's study, reasons in addition to linguistic or cultural ones also include "limited content knowledge, personal tendency and preference, learning goals, identity as a less competent member, outsider or marginal status, role as a relative newcomer, role as someone with limited English imposed by others, and instructor's pedagogical style" (p. 589). This illuminates our understanding further because gender, culture, or language alone could not sufficiently explain their behaviors. Understanding all of these complex and interdependent reasons prevents us from essentializing the problem, and guards our students from being essentialized.

In a study involving 197 Japanese intermediate English as foreign language (EFL) learners in a first-year English degree course, Harumi (2011) examined the characteristics and culture-specific uses of silence in Japanese classrooms. Her findings affirm that there are various functions for its use that are unique and cannot all be attributed to lack of content knowledge or competence in English. She 
argues that it is necessary "to look at silence as a significant social component in its own right since talk and silence mutually influence each other" (p. 261). The functions and sources for silence can be positively or negatively interpreted and misinterpreted across cultures. Her study concludes that a number of interrelated factors may explain how learner silence is rooted in linguistic, psychological, and sociocultural factors, including an individual's unique communicative style. Although each factor can be argued independently as a reason for classroom silence, they appear to be connected, and "cultural norms, especially groupism, often underlie learners' silence” (p. 268). Thus, Harumi expresses the need to include learners' expectations as part of the dynamic teaching and learning process, and states that students are more "likely to respond better to teachers who empathize with their use of silence" (p. 268).

In summary, the literature review indicates that there are many more individual and contextual factors, in addition to linguistic and cultural factors, that contribute to students' silence or nonparticipation in classes conducted in English. These include personality and learning style, prior educational experiences, and silencing factors from peers and teachers, not just a lack of confidence in English language proficiency and cultural background.

The above review helps to gain insight into Japanese students' silence, but there is much more room to explore Japanese students' silence or non-participation. Few previous studies have examined perceptions of silence by directly asking Japanese university students studying in Japan; rather, significant silence issues have emerged as part of their classroom participation experiences mostly by researching Japanese students who study overseas. To fill the research gap, our study focuses on the silence aspect but addresses the issue of silence from a broader perspective by asking Japanese university students studying in their own countries about their perceptions of silence and their comfort level and communication strategies related to silence. We believe this study can add to our understanding some Japanese international students' seemingly passive classroom participation in English-speaking countries. While silence is ambiguous in nature, this study contributes to the literature by demystifying its presence and providing insight into some of the 
reasons behind the silence. This study can suggest silence as an alternative form of engaged learning and active participation.

\section{RESEARCH METHOD}

In fall 2013, 45 Japanese university students who were studying in Japan were surveyed about their views of silence in general. They were freshmen or sophomore English major students who were enrolled in a required English class at a Japanese university. The professor, who was Japanese, was contacted by the first author, with whom she knew and had a professional relationship. According to the professor, most of them were relatively proficient in English.

The primary source of data in this study was a short survey which consisted of two open-ended questions: (1) When you ask a question of someone, how long do you wait for a response? (2) Do you feel uncomfortable with silence? If so, why and what do you do to avoid silence? Upon the researcher's request, the professor distributed the hard copy survey to the students. They were asked to answer in English. All of the students in the class filled out the survey.

In the initial data analysis stage, the raw data were closely examined to see if there were any unusable data. We found all data usable based on the criteria that there were not any missing responses and the responses provided by the students were relevant to the questions being asked. The data were divided into the three categories: comfortable, uncomfortable with silence, and it depends. The researchers individually analyzed the sorted data by categorizing them into the three categories and then adding emerging new themes and our own interpretation without specifying one way to analyze the data (Creswell, 2013). This method was chosen to avoid influencing each other's analysis and to be able to use our own unique ways of interpreting the same data with diverse perspectives. The lead researcher reviewed the individual reports and asked follow-up questions by exchanging several e-mails and web conference call meetings. The researchers then met together via a web conference call to read the initial analysis together. Several initial themes were reviewed and re-categorized together during the meeting. The codeveloped analysis reports and themes developed by the lead 
researcher were sent back to the four co-researchers again. The researchers were asked to add any interesting or surprising findings to the analysis. The lead researcher later finalized the Japanese university student survey findings and shared them with the coresearchers for their final confirmation.

\section{RESULTS}

This study attempted to investigate Japanese university students' comfort levels with silence by inquiring to what degree students could withstand the presence of silence within a conversation, and what strategies, if any, they employed to avoid silence. The participant responses illustrated various dimensions of silence.

\section{Wait Time for a Response}

The survey asked participants how long they waited for a response if they asked a question someone. As shown in the Table 1, 20 of the 45 participants would wait either one minute or more for a response when they pose a question to someone. On the other hand, 18 participants stated that they would wait less than a minute for a response, yet they did not mention a specific time for how long they would wait; some stated five seconds, others 10 seconds. In addition, eight participants stated that they would wait hours or a whole day until the person is ready to generate an answer. One person made a distinction related to context: If it is a serious question, the respondent would wait longer; if it is not, the respondent would not wait as long.

\section{Table 1: Length of Time for a Response}

\begin{tabular}{lc}
\hline Length of Time & No. of respondents \\
\hline Equal or more than one minute & 20 \\
Less than one minute & 18 \\
Other (i.e., one day, depends on the question) & 7 \\
Total Number of Respondents & 45 \\
\hline
\end{tabular}

\section{Comfort Level with Silence}

The survey also asked participants whether they feel comfortable with silence or not. If they felt uncomfortable, they were 
asked to elaborate on their reasons and the communication compensation strategies they may use to avoid silence. As shown in Table 2, of the 45 participants, 16 stated that they felt comfortable, 15 stated that they felt uncomfortable, and 14 stated that it depended on the person, situation, or context.

\section{Table 2: Comfort Level with Silence}

Comfort level No. of respondents

Comfortable 16

Uncomfortable $\quad 15$

Depends $\quad 14$

Total Number of Respondents $\quad 45$

Participants seemed clearly divided: they were either very comfortable with silence or very uncomfortable with silence. Participants who stated "it depends" distinguished between whether the conversant was a close friend or someone they were not familiar with.

Comfortable with silence. The 16 participants who stated that they were comfortable with silence gave several reasons why they were not bothered by silence, as summarized in Table 3 .

\section{Table 3: Reasons for Being Comfortable with Silence}

\begin{tabular}{lc}
\hline Reasons & No. of comments \\
\hline No discomfort when talking with friends & 12 \\
No need to talk when it is not necessary & 4 \\
Love silence & 4 \\
Total Number of Comments & 20 \\
\hline
\end{tabular}

The most frequent theme (12 out of 20 comments) was that they did not feel uncomfortable with silence when they talked with friends. When the participants had already built up a rapport with someone, as with friends, it was not an uncomfortable situation. This theme was echoed by several participants who noted "it depends." They commented that they would not feel uncomfortable with silence 
if they are talking to a friend. Four participants reported that they feel comfortable with silence when they do not see talking as necessary or they simply do not feel like talking. Several other participants indicated that they prefer silence in general, so silence does not create any discomfort.

Uncomfortable with Silence. Two major themes emerged from the analysis of why participants felt uncomfortable with silence. One of the themes was that they could not bear silence or hated silence (three responses). Another theme was that they loved to talk in general (five responses). Two opposite feelings were voiced; participants either "hated" silence or "loved" talking. Participants reported detailed reasons for their discomfort with silence. Some stated they felt impatient or awkward with silence. One respondent questioned the meaning of being with someone if they were not going to engage in some kind of conversation: "What was the purpose of the encounter if no talk was present?" They equated conversation or communication with simply talking/speaking with someone. Table 4 summarizes participants' reasons for being uncomfortable with silence.

\section{Table 4: Reasons for Being Uncomfortable with Silence}

\begin{tabular}{lc}
\hline Reasons & No. of comments \\
\hline Cannot bear silence/Hates silence & 3 \\
Is impatient about conversation (wants to & 3 \\
talk) & 1 \\
Wants to have a lively conversation & \\
Sees no meaning to being with someone if & 1 \\
silent & 8 \\
Total Number of Comments & \\
\hline
\end{tabular}

\section{Strategies to Avoid Silence}

Participants were also asked what they do to ensure that a conversation runs smoothly by breaking up a silent moment if they feel uncomfortable with silence. As Table 5 indicates, three major themes emerged from the responses. The most common strategy reported by participants (seven of 12) was shifting to an easier topic 
to avoid silence and engaging in conversation without staying on the initial topic.

\section{Table 5: Things Being Done to Avoid Silence}

\begin{tabular}{lc}
\hline Things to Do & No. of comments \\
\hline Shift topic to an easier topic & 7 \\
Continue by talking more/Elaborate on topic & 3 \\
$\quad$ Ask follow-up questions about the topic (2) & \\
$\quad$ Talk more about the topic (1) & 2 \\
Use phone & 12 \\
Total Number of Comments
\end{tabular}

Participants use various strategies to shift the topic, including making small talk and talking about the weather. On the other hand, three students reported that they make an effort to continue with the same topic by talking more along the same line of the conversation or by asking follow-up questions to help the interlocutor, the person who takes part in a dialogue or conversation, to continue. Two respondents said that they use a phone when they feel uncomfortable with silence to avoid the silent moment. The participants who use technology to avoid silence stated they use their smartphone to start texting or surfing with various applications.

\section{DISCUSSION}

The authors in this study investigated Japanese university students' views of silence. These included their comfort level with silence, the reasoning behind their comfort level, and the contextual conditions that affect whether or not they find a silent moment comfortable. The study allowed us to understand that there are many interrelated factors that influence both silence and talk. Based on the results, several important findings with implications for teaching Japanese students emerged. These findings may also apply to other international students in U.S. classrooms. 
Silence varies on a highly individualized, contextualized basis, not only by culture.

One interesting finding of this study is that individuals and individualistic factors play a role in whether a person describes him/herself as enjoying talk or enjoying silence. Participant responses were evenly divided as comfortable with silence, uncomfortable with silence, or it depends on the familiarity with the person. Wait time for a response was almost evenly divided between either greater than or less than one minute. The results suggest that there is a relative and subjective nature to time and a tolerance level that may be related to a person's demeanor (patient or impatient) when a question is asked and a response is expected. This exemplifies how interpersonal communication and silence varies not only culturally but on a highly individualized basis. This is consistent with Harumi's (2011) conclusion that not only linguistic and sociocultural factors but an individual's unique communicative style is a determining factor in relation to silence. Japanese students are, therefore, not much different from American students in terms of valuing talking and enjoying talk. If they remain silent in classrooms, multiple complex, contextual, and individual factors in addition to language and culture may be at play (Balogh, Kraker, Nielson, Kim, \& Marku, 2014; Kim, 2008; Morita, 2004).

These varied perceptions of silence by Japanese students lead to an important classroom implication. As Bista (2012) stated, "As silence has multiple meanings in any teaching and learning classroom, teachers should not take the notion of silence literally. When students are silent, one cannot assume they are not learning" (p. 81). Teachers need to reflect critically on classroom participation and silence in light of a multitude of factors, including their students' ethnic, linguistic, and cultural backgrounds; their personal traits; and the classroom environment (Kim, 2008). As Harumi (2011) stated, students are more "likely to respond better to teachers who empathize with their use of silence" (p. 268).

\section{Silence does not always mean non-communication.}

About half of the survey respondents stated that they valued silence and did not feel awkward at all during a silent moment. Those comfortable with silence were willing to give enough wait time for 
the response to a question. This finding exemplifies the notion that active engagement does not always have to be verbal (Kim, 2008; Tatar, 2005a, 2005b). Studies (Kim, 2008; Nakane, 2005) show that many people break the silence by speaking up, yet it is not an easy task to do. Some people feel more comfortable with a silent moment than making a constant effort to avoid silence. Voice and silence are not necessarily opposites. Narratives are made up of both voice and silence, and they may emphasize personal, cultural, or societal traits; ways of thinking; and ways of being, which may include a space for silence. "Talk does not always imply voice" (p. 90), as Fivush (2010) states, and silence does not always mean non-communication (Duff, 2002; Kim, 2008).

This finding implies that instructors of international students may need to consider the concept of "silent participation through attentive listening and careful reflection" (p. 212) proposed by Kim (2008). It would be acceptable to allow students to remain silent as long as they show other signs of active participation rather than pushing them to speak for the sake of speaking, especially if they are new to the U.S. classroom with the extreme initial stress in a foreign environment (Brown, 2008; Kim, 2006, 2008, 2014). This concept considers listening with empathy; an active and draining process which accepts that non-verbal communication, including silence, can be just as communicative as words (Knapp, Hall, \& Horgan, 2014). Allowing them to remain silent in the beginning can ease the adjustment of international students to the class while understanding the required oral classroom participation and observing classroom participation patterns between the teacher and peers and among peers. Therefore, class participation can be graded gradually, moving from non-grading to grading by actual participation by speaking up in class.

Instructors may use other activities to improve class participation for international students in U.S. classrooms. These activities include ice breakers; small group work, with several variations; and the use of technology. Using an ice-breaker at the beginning of the semester allows students to get to know each other and opens lines of communication. This activity might make students more comfortable when they are expected to present their ideas orally to the class. 
Small group work offers many options. For example, small discussion groups can be created that have the same members each time. These standing groups, when utilized often, will foster a more relaxed atmosphere as students become more comfortable with their group mates. Having one major group project that lasts the entire semester may help students feel more comfortable with silence and talking with peers. By the time the final project is presented, the students will be familiar with each other and those who were less comfortable with silence in the beginning will have the support of other group members. The professor can establish an expectation that "everyone must contribute during the small group discussions," even if the contribution is a very short comment.

Small groups may vary in their leadership. For example, each time the group meets, there can be a discussion leader who facilitates the discussion. The following discussion leader role expectations can be established and shared by the professor:

(a) There will be one discussion leader per week and per group.

(b) Discussion leaders within the group will rotate each week.

(c) Once the rotation is completed, it will start all over again.

(d) The discussion leader will monitor who speaks and for how long.

(e) $S /$ he will encourage all members to participate with a positive attitude.

Groups can then be called on to report their work to the class as a whole. Giving students the option of nominating one student per class to speak for the group allows all students to contribute to the creation of ideas without having the pressure to present every week. This speaker responsibility could rotate throughout the group, so everyone gets a turn. To accommodate all types of students, the teacher may assign different roles within the group. For example, one student (who enjoys talking the most) can be the lead speaker and another one (who prefers to observe and listen) can be the lead notetaker. It is important for the teacher to recognize early on which students prefer silence or no silence in order to coordinate projects this way.

Another option is to allow students to write down their ideas before they share their work in both small and large group settings. Because oral participation is expected in the American university classroom, it is difficult for those who do not normally talk a lot to 
speak up in class. If students write down their ideas first, they have a chance to see their thoughts on paper and can rethink or adjust them when speaking. Students can be given the choice to read what they have written rather than having to summarize it.

Technology may also be used to improve class participation for international students in U.S. classrooms. With technology, instructors can use alternative ways to assess participation, such as grading participation in online discussion threads as well as face-toface classroom participation. Professors may, for example, create an online class blog and have students participated in different discussions and forums at least twice a week as part of their participation grade. 'I loved it,' reports one author of the present study who had this experience, 'because I had the chance to think at my own pace about what my classmates were discussing and respond with my own thoughts. When I could see my thoughts "on paper," I felt much more comfortable bringing up different points and questioning ideas.'

The participants in this study were asked what they do if they feel uncomfortable with silence, and they most commonly reported shifting to an easier topic. This finding also has implications for the classroom teacher, who may, in response, prepare multiple discussion questions on diverse topics and instruct students or groups to choose those topics they find most interesting or easiest to talk about. This would keep the conversation going for those who need this type of assistance. Professors could require one group each week to submit discussion questions on the topic to be studied rather than always provide them himself/herself. When putting the questions together, the small groups, including the "silent" students, would engage in dialogue. Jigsaw activities are another way to facilitate the participation of silent students. The class is formed into several groups, each specializing in a different topic or aspect of a topic. Then students count off from 1 to 4 (depending on the number of students) and form new groups, with the $1 \mathrm{~s}$ in one group, $2 \mathrm{~s}$ in a second group, etc. Silent students are encouraged to share what they know because they are the experts on their topic or aspect of their topic.

On the other hand, three students reported that, in order to avoid silence, they follow the same line of conversation or ask follow- 
up questions to help the interlocutor continue. Students may use a similar strategy in the classroom to determine if their peers do not understand the topic. By elaborating further or asking thoughtprovoking questions, students within a group can work together to gain knowledge on the topic at hand. One who has a good handle on the topic can utilize the silence to elaborate more to help the others understand.

\section{The interlocutor, not the topic of conversation or the discussion topic, is the significant factor.}

The results gathered from Japanese participants who were comfortable with silence suggest the importance of the degree of relationship. Talking was deemed unnecessary between individuals involved in an exchange if they were friends. However, if the relationship was more formal, as with a professor, they might feel uncomfortable. The interlocutor was the significant factor, not the topic of conversation or the discussion topic. This finding suggests that a wider variety of topics can be discussed with a person who is more familiar than with one who is less familiar. When the comfort level is high with another person, we can approach more topics and accept more periods of silence throughout an interchange of communication.

\section{CLASSROOM AND RESEARCH IMPLICATIONS}

Critical classroom implications can be inferred from the results of this study. Instructors must devote time and energy to creating a warm, welcoming environment for students to promote a sense of community in the classroom and with each other. This seems especially important when working with international students whose original culture may be more relationship-based. Through a friendly and open atmosphere, students will not be intimidated by each other and/or the learning environment. If university instructors show their sincere interest in international students, and acknowledge their contributions in the classroom, this can result in a sense of belonging in the classroom community (Morita, 2004) as well as in increased oral participation (Kim, 2008). 
This study explored the roles of silence and its meaning perceived by Japanese students by surveying university students in Japan as a way to understand possible Japanese students' perceptions and behaviors in the U.S. classroom. However, the study does not claim to provide a full picture of the entire Japanese university population. It presents the views of only the participants who were surveyed. Although this study had limitations, our results suggest important implications for research. Future studies could include a larger sample size. The study also included only two focused questions related to silence. Answers to these questions may not provide a full representation of how the participants would actually respond in place of silence. Focus group discussions or individual interviews could be conducted to gain more depth of understanding of participants' views on silence. Views of students from other countries and cultures could also be surveyed in order to examine silence from different and broader perspectives. The data collected could further be supported by observing the individual's responses to silence in an ordinary, everyday environment. This may provide a more natural example of how individuals interact in the real world. In addition, classroom observations could be conducted to gain insight into the same individuals' response to silence this time in an academic and professional setting.

\section{REFERENCES}

Balogh, K., Kraker, S., Nielson, V, Kim, S., \& Marku, L. (2014). Use of space in diverse classrooms perceived by students: Avoiding cultural misunderstanding. Language and Communication Quarterly, 3(2), 65-80.

Kim, S. (2006). Academic oral communication needs of East Asian international graduate students in non-science and nonengineering fields. English for Specific Purposes, 25, 479-489.

Kim, S. (2008). Silent participation: East Asian International graduate students' views on active classroom participation. Journal on Excellence in College Teaching, 19(2/3), 199-220.

Bista, K. (2012). Silence in teaching and learning: Perspectives of a Nepalese graduate student. College Teaching, 60, 76-82. 
Brown, L. (2008). The incidence of study-related stress in international students in the initial stage of the international sojourn. Journal of Studies in International Education, 12(1), $5-28$.

Creswell, J. (2013). Research design: Quantitative, qualitative and mixed methods. Thousand Oaks, CA: Sage.

Duff, P. A. (2002). The discursive co-construction of knowledge, identity, and difference: An ethnography of communication in the high school mainstream. Applied Linguistics, 23(3), 289322.

Fivush, R. (2010). Speaking silence: The social construction of silence in autobiographical and cultural narratives. Memory, $18(2), 88-98$.

Harumi, S. (2011). Classroom silence: Voices from Japanese EFL learners. ELT Journal, 65(3), 260-269.

Institute of International Education (2012). Top 25 places of origin of international students, 2010/11-2011/12." Open Doors Report on International Educational Exchange. Retrieved from http://www.iie.org/opendoorshttp://www.iie.org/opendoors

Jones, S. (2011). Speech is silver, silence is golden: The cultural importance of silence in Japan. The ANU Undergraduate Research Journal, 3, 17-27. Retrieved from http://eview.anu.edu.au/anuuj/vol3_11/pdf4/ch02.pdfhttp://evi ew.anu.edu.au/anuuj/vol3_11/pdf4/ch02.pdf

Knapp, M. L., Hall, J. A., \& Horgan, T. G. (2014). Nonverbal communication in human interaction. Boston, MA: Cengage Learning.

Lebra, T. (1987). The cultural significance of silence in Japanese communication. Multilingua, 6, 343-357.

Lebra, T. (2007). The cultural significance of silence in Japanese communication. In T. Lebra (Ed.). Identity, gender, and status in Japan: Collected papers of Takie Lebra. Folkestone, Kent, UK: Global Oriental.

Mayuzumi, K., Motobayashi, K., Nagayama, C., \& Takeuchi, M. (2007). Transforming diversity in Canadian higher education: A dialogue of Japanese women graduate students. Teaching in Higher Education, 12(5/6), 581-592. 
Morita, N. (2004). Negotiating participation and identity in second language academic communities. TESOL Quarterly, 38(4), 573-603.

Nakane, I. (2005). Negotiating silence and speech in the classroom. Multilingua-Journal of Cross-Cultural and Interlanguage Communication, 24(1/2), 75-100.

Schultz, K. (2012). The fullness of silence in the classroom.

Phi Delta Kappa, 80, 12-16.

Tatar, S. (2005a). Why keep silent? The classroom participation experiences of non-native- English-speaking students. Language and Intercultural Communication, 5(3/4), 284-293.

Tatar, S. (2005b). Classroom participation by international students: The case of Turkish graduate students. Journal of Studies in International Education, 9(4), 337-355.

SOONHYANG KIM, Ph.D., is an assistant professor of TESOL at University of North Florida, Jacksonville Florida, U.S.A. Her research interest includes professional dispositions in teacher education, oral academic literacy development, non-native English-speaking professional development issues, and on-line education.

E-mail: S.Kim@unf.edu

BURCU ATES, Ph.D., is an assistant professor of TESOL education at Sam Houston State University, Huntsville, Texas, USA. Her research interests include pre- and in-service teachers' professional development, international service-learning, non-native Englishspeaking professionals, and World Englishes.

E-mail: ates@shsu.edu

YURIMI GRIGSBY, Ph.D., is an associate professor in the Department of Teaching, Learning, and Diversity at Concordia University Chicago. Her research interests include: Heritage language maintenance/loss and professional dispositions.

E-mail: yurimi.grigsby@cuchicago.edu

STEFANI KRAKER is currently completing her Masters of Arts in Speech-Language Pathology at Queens College, City University of 
New York in Flushing, New York, USA. She obtained her Bachelor of Arts in Communication Sciences and Disorders at Pace University in New York, New York, USA.

E-mail: stefani.kraker65@ qmail.cuny.edu

TIMOTHY A. MICEK, DA, is an associate professor in the Division of Education and the director of the MATESOL program at Ohio Dominican University in Columbus, Ohio. His research interests include program development and administration, clinical supervision, professionalism, service-learning, and reflective practice. E-mail: micekt@ohiodominican.edu

Manuscript submitted: November 5, 2015 Manuscript Revised: January 4, 2016 Accepted for publication: March 5, 2016 